\title{
Article \\ Sturgeon Meat and Caviar Quality from Different Cultured Species
}

\author{
Annalaura Lopez $₫$, Mauro Vasconi $₫$, Federica Bellagamba $₫$, Tiziana Mentasti and \\ Vittorio Maria Moretti * \\ Department of Veterinary Medicine-Università degli Studi di Milano, Via dell'Università 6, 26900 Lodi, Italy; \\ annalaura.lopez@unimi.it (A.L.); mauro.vasconi@unimi.it (M.V.); federica.bellagamba@unimi.it (F.B.); \\ tiziana.mentasti@unimi.it (T.M.) \\ * Correspondence: vittorio.moretti@unimi.it; Tel.: +39-0250315760; Fax: +39-0250315746
}

Received: 18 October 2019; Accepted: 5 February 2020; Published: 7 February 2020

\begin{abstract}
Sturgeon raw eggs, caviar and meat obtained from different species reared in an Italian production plant were evaluated for their chemical composition, in order to improve their appreciation on the market and to detect any eventual distinctness related to the species. Mainly, fatty acid (FA) profile of eggs and caviar, determined by Gas-Chromatography coupled to Flame Ionization Detection, showed variability in the interspecific comparison, highlighted by chemometric methods (Linear Discriminant Analysis). Generally, all samples showed a prevalence of unsaturated fatty acids with respect to saturated ones, reaching a content of polyunsaturated fatty acids (PUFA) between the $40 \%$ and the $50 \%$ of total FA. A remarkable presence of n3 series PUFA was detected in all samples and a selective deposition of many FA into eggs' cellular membranes, yolk lipid and body fat reserves, imputable to the different biological role of single FA during sturgeon reproduction, was evidenced. Chemical composition of sturgeon flesh samples evidenced a high-protein and medium-fat content, characterized by a FA profile of high nutritional value. Moreover, color parameters (redness, yellowness, brightness, Chroma) were measured on sturgeon fillets, showing many species-specific characteristics of sturgeon meat.
\end{abstract}

Keywords: sturgeon; caviar; fish eggs; sturgeon meat; aquaculture; chemical composition; fatty acids

\section{Introduction}

Sturgeons are fish species belonging to the Acipenseridae family originally distributed throughout the Northern hemisphere. In Europe, they inhabited mainly in the large river systems of the Ponto-Caspian region and the Black, Azov and the Caspian seas. The construction of barriers and dams on rivers during the years has largely contributed to prevent the migration of these species during the reproductive season, as they live in brackish waters and migrate to freshwater rivers for spawning. Moreover, the realization of quarries for the extraction of construction materials and water pollution have altered typical habitats dedicated to sturgeons' reproduction. Furthermore, the over-exploitation of the natural resources for caviar production has contributed to a worldwide decline of fish stocks. Thus, sturgeons species are now listed in Annex I and II of the Convention on International Trade in Endangered Species (CITES) and they are protected from the over-exploitation in all range states, with an exception for some Countries (mainly, Russia, Iran, Kazakhstan, Canada, USA) [1] where legal fisheries for limited quantities are still allowed. In 1869, the artificial reproduction of sturgeon used to support the natural populations began, with the pioneering work of Ovsyannikov on Sterlet (A. ruthenus) in USSR. The basic techniques and practices of artificial reproduction of sturgeon were then developed in the 1940's and 50's by Stroganov [2]. Only in recent decades specific farming techniques for sturgeons have been established, and under the strong pressure of market demand for 
caviar, the sturgeon farming industry has increased $[1,3,4]$, so that, since the end of the 20th century, it has been the fastest growing aquaculture sector. As recently reported by Bronzi et al. [1], a total of 2329 commercial sturgeon farms were recorded by 2017, with an increase of 7\% compared to 2016. Nowadays, sturgeon farming exceeds fisheries, with China as the worldwide leader (79,638 tons (t) of sturgeon biomass production in 2017), followed by Russia (6800 t), Armenia (6000 t) and Iran (2514 t). Italy is the European leader in sturgeon farming, with a biomass production of 850 tons in 2017 [1]. In Europe, sturgeon farming started as a meat-oriented production, but nowadays it has mainly shifted to caviar production, representing a more profitable source of income. On the contrary, in other countries such as China, sturgeon farming is still mainly oriented toward meat production. It has been estimated that global caviar production from aquaculture recorded amounts around 364 tons in 2017 [1]. In this context, Italy is the first European producer, achieving a remarkable caviar production of 43 tons in 2017, being second just to China and Russia [1]. CITES trade data (2018) reported that Italy exports both meat and caviar from many species [5] and the most commonly farmed sturgeon species in Italy are White sturgeon (Acipenser transmontanus), Russian sturgeon (Acipenser gueldenstaedtii), Siberian sturgeon (Acipenser baerii), Adriatic sturgeon (Acipenser naccarii), Beluga sturgeon (Huso huso) and Stellate sturgeon (Acipenser stellatus) [6]. Caviar and meat obtained from different species of sturgeons are known to have different market values. The most renowned and valuable caviars are named Beluga, from H. huso, Osetra, from A. gueldenstaedtii, and Sevruga, from A. stellatus and A. persicus. On the other hand, according to the producers' opinion, the highest quality for sturgeon meat is obtained from $A$. transmontanus sturgeons. However, sturgeon meat is still considered a secondary and/or by-product of caviar in Italy, where consumers seem to avoid it, likely because they are not familiar with this product. Thus, at present, most of the sturgeon meat produced in Italy is frozen and sold abroad, especially in the Eastern European and Russian markets, where consumers actually appreciate this product, being more accustomed with it.

The success achieved in the production of caviar obtained from aquaculture has gradually promoted the study of its chemical characteristics, mainly aiming to compare the quality of caviar products with different origin (aquaculture versus fisheries, or caviar from different species). Several studies have been carried out on the determination of fatty acid (FA) profile, proximate composition, volatile compounds and amino acid profile of caviar [7,8]. The chemical composition of caviar is influenced by various factors, such as the species, the age of the sturgeon, the stage of maturation of the eggs at the time of harvest, the type of diet and the origin of animals [8-12]. In general, caviar is a food characterized by a high nutritional profile, as it is rich in essential fatty acids (EFAs) and high biological value proteins $[10,13,14]$. The chemical quality of meat obtained from different sturgeon species [15] or hybrids [16] of different ages and weights [17] has been investigated during past years. All the authors found that the meat of farmed sturgeons contained variable amounts of lipid, depending on the species and the size of specimens. Protein content revealed a high biological value, depending on the amino acid composition. Fatty acid composition of sturgeon meat resulted in valuable omega-3 fatty acid contents, especially eicosapentanoic acid (EPA) and docosahexaenoic acid (DHA), mirroring the FA composition of the diet (commercial or experimental).

Thus, the aim of this study was to evaluate the composition (chemical and lipid composition, color parameters) of caviar and meat obtained from different species of sturgeon reared in an Italian production plant, in order to characterize these precious products and to promote them on the market. 


\section{Results}

\subsection{Proximate and Fatty Acid Composition of Eggs and Caviar}

The proximate composition of raw eggs and caviar obtained after six months of can maturation, from three sturgeon species (A. baerii, A. gueldenstaedtii and A. transmontanus), is presented in Table 1.

Table 1. Proximate composition (g/100 g) of fresh egg samples, before salting and canning, and of caviar samples, after six months of can maturation, from different sturgeon species. Data are expressed as $\mathrm{g} / 100 \mathrm{~g}$, mean \pm standard deviation.

\begin{tabular}{|c|c|c|c|c|c|c|}
\hline \multirow[b]{2}{*}{ Sturgeon Species } & \multicolumn{3}{|c|}{ Eggs } & \multicolumn{3}{|c|}{ Caviar } \\
\hline & $\begin{array}{l}\text { Siberian } \\
\text { (A. baerii) }\end{array}$ & $\begin{array}{c}\text { Russian } \\
\text { (A. gueldenstaedtii) }\end{array}$ & $\begin{array}{c}\text { White } \\
\text { (A. transmontanus) }\end{array}$ & $\begin{array}{l}\text { Siberian } \\
\text { (A. baerii) }\end{array}$ & $\begin{array}{c}\text { Russian } \\
\text { (A. gueldenstaedtii) }\end{array}$ & $\begin{array}{c}\text { White } \\
\text { (A.transmontanus) }\end{array}$ \\
\hline \multicolumn{7}{|c|}{ Chemical composition } \\
\hline Moisture $\mathrm{g} / \mathbf{1 0 0} \mathrm{g}$ & $59.5 \pm 0.9^{C}$ & $53.9 \pm 2.0^{\mathrm{A}}$ & $57.1 \pm 1.3^{\mathrm{B}}$ & $57.3 \pm 2.5^{\mathrm{B}}$ & $52.7 \pm 2.2^{\mathrm{A}}$ & $54.6 \pm 0.9^{\mathrm{A}, \mathrm{B}}$ \\
\hline Protein g/100 g & $23.8 \pm 0.8$ & $24.1 \pm 1.0$ & $24.9 \pm 0.6$ & $23.9 \pm 2.2$ & $24.7 \pm 1.2$ & $24.0 \pm 1.3$ \\
\hline
\end{tabular}

In Table 1, we can see that in egg samples, moisture content resulted higher in Siberian sturgeon eggs (59.5\%), followed by White sturgeon (57.1\%) and Russian sturgeon (53.9\%) eggs. Protein level, indeed, was practically constant, ranging from $23.8 \%$ to $24.9 \%$, without differences among species. Lipid content was higher in Russian (19.7\%) and White (16.1\%) sturgeon eggs than in Siberian sturgeon (14.9\%) eggs. Ash did not show significant differences. Regarding caviar composition, our results were comparable with those previously reported in literature about caviar from farmed sturgeons $[7,13,18]$. The protein content did not show significant differences between the examined species, ranging between $23.9 \%$ and $24.7 \%$, according to the results of our previous studies [7]. Conversely, lipid content showed some significant differences, with A. gueldenstaedtii caviar significantly fatter (19.1\%) than A. baerii (14.9\%) and A. transmontanus (17.7\%) caviar. Comparing raw eggs and caviar composition for each species, these two matrices differed for ash and moisture content. It can be suggested that a reasonable loss of moisture and an increase of ash occurred during caviar maturation, due to salt addition and to ripening processes.

Fatty acid composition of raw eggs and caviar in the three sturgeon species under investigation is shown in Table 2.

The fatty acids profile detected in our samples matched with the general pattern reported in literature for fatty acid composition of sturgeon eggs and caviar [7,10,12,13,19-21]. Among the saturated fatty acids (SFA), palmitic acid (16:0) proved to be the most abundant in both eggs and caviar samples, regardless of the species considered, according to the results of several previous publications $[7,9,10,12,22]$. The main monounsaturated fatty acid (MUFA) was represented by oleic acid (18:1 n9) in all samples and many significant differences emerged among caviar samples, with White sturgeon caviar showing the highest value (30.6\%), followed by Siberian sturgeon (28.4\%) and then Russian sturgeon (25.4\%) caviar. There is a general agreement in arguing that oleic acid is the most abundant fatty acid in sturgeon eggs, regardless of their origin and species, among the scientific literature available in the field $[7,9,10,12,22]$. This is not surprising, since it is well known that oleic acid represents the main source of energy during embryonic development in ova [23], even if a recent study has shown how its content could decrease with the age of sturgeon [22]. Considering the polyunsaturated fatty acids (PUFA) of the n6 series, the predominant one was linoleic acid (LA, 18:2 n6) in all samples, ranging from $13.4 \%$ to $20 \%$ in eggs and from $12.8 \%$ to $16.8 \%$ in caviar. In both cases, significant differences were observed among the different species under investigation. The high content of LA in sturgeon eggs and caviar is supported by literature data, which show a high percentage of linoleic acid (significantly greater than in wild samples) in caviar from cultured sturgeon, 
mainly due to the lipid composition of commercial diets [7,9-11,19,24]. It is well known that linoleic acid is widely represented in oils of vegetable origin (such as soy oil, sunflower oil, rapeseed oil, corn oil) commonly used in commercial feed as an alternative lipid source, to partial replacement of fish oils, more expensive and less eco-sustainable. For this reason, some authors previously reported that a high LA content can be used as an indicator of the origin of wild versus farmed caviar [12]. Arachidonic acid (ARA, 20:4 n6) was the second most abundant n6 series fatty acid, ranging from $1.7 \%$ to $2.3 \%$ in eggs and from $1.8 \%$ to $2.4 \%$ in caviar samples, with some differences among the species. As well as for LA, the level of ARA in caviar depends on the feed source supplied to sturgeons. Although ARA is the second most predominant among the n6 PUFA, our results showed significantly lower amounts than what is described in literature for wild caviar $[9,11,19,24]$. This can be imputed to the fact that ARA is highly present inside the aquatic trophic chains, especially in some algae and in some crustaceans [25] that represent the natural diet sources of wild sturgeons. Among the n3 series polyunsaturated fatty acids, the analyzed samples showed a clear prevalence of eicosapentaenoic acid (EPA, 20:5 n3) and docosahexaenoic acid (DHA, 22:6 n3) in all the species. In both the matrices, Russian sturgeon samples resulted the most enriched in EPA (6.5\%), whereas Siberian sturgeon eggs and caviar showed the highest amount of DHA (15.7\% and 14.0\%, respectively). The selective deposition of EPA and DHA in caviar resulted to be high in any case, regardless of the type of diet supplied to fish. Caprino et al. [7] reported similar concentrations of EPA and DHA in caviar from sturgeons fed with two different experimental diets, one containing squid oil and one soybean oil as the main lipid source. Similar values of EPA and DHA have also been demonstrated in caviar of wild and farmed sturgeons, confirming the low influence of diet composition on the accumulation of these two fatty acids in fish eggs $[10,19]$. A positive correlation between the EPA and DHA content in fish eggs and some reproductive parameters, such as the fertilization and hatching rate [26], have been also highlighted and these FA are known to play an important role in the embryonic development of fish [27-29].

In order to evaluate if a discrimination of samples from different species based on their fatty acid composition was feasible, a multivariate statistical method was developed and employed. Since no great differences were found in fatty acids composition of raw eggs and caviar within the same species, the Acipenser species was considered as the only discriminant factor, and eggs and caviar from the same species were considered as a unique group. In Figure 1, the Canonical Plot of the Linear Discriminant Analysis (LDA) performed on fatty acids data is shown. In Table 3, the results of analysis of variance (ANOVA) performed on Canonical1 and Canonical2 scores as factors among groups are shown. 
Table 2. Fatty acid profile (g/100 g of fatty acids) of fresh egg samples, before salting and canning, and caviar samples, after six months of can maturation, from three different sturgeon species. Data are expressed as $\mathrm{g} / 100 \mathrm{~g}$, mean \pm standard deviation.

\begin{tabular}{|c|c|c|c|c|c|c|c|c|}
\hline \multirow[b]{2}{*}{ Sturgeon Species } & \multicolumn{4}{|c|}{ Eggs } & \multicolumn{3}{|c|}{ Caviar } & \\
\hline & Siberian A. baerii & $\begin{array}{c}\text { Russian } A . \\
\text { gueldenstaedtii }\end{array}$ & \multicolumn{2}{|l|}{$\begin{array}{c}\text { White } A . \\
\text { transmontanus }\end{array}$} & Siberian A. baerii & $\begin{array}{c}\text { Russian } A . \\
\text { gueldenstaedtii }\end{array}$ & $\begin{array}{c}\text { White } A \text {. } \\
\text { transmontanus }\end{array}$ & \\
\hline $\mathbf{n}$ & 5 & 5 & \multicolumn{2}{|l|}{5} & 8 & 11 & 12 & \\
\hline \multicolumn{9}{|c|}{ Fatty acids $(\mathrm{g} / 100 \mathrm{~g})$} \\
\hline $14: 0$ & $0.9 \pm 0.1^{\mathrm{B}}$ & $1.3 \pm 0.1^{\mathrm{A}}$ & $1.4 \pm 0.1^{\mathrm{A}}$ & ** & $0.9 \pm 0.1^{C}$ & $1.2 \pm 0.1^{\mathrm{B}}$ & $1.4 \pm 0.2^{\mathrm{A}}$ & ** \\
\hline $16: 0$ & $18.7 \pm 3.3$ & $16.5 \pm 0.6$ & $17.4 \pm 0.6$ & & $17.5 \pm 0.7$ & $17.0 \pm 1.2$ & $16.6 \pm 0.8$ & \\
\hline $18: 0$ & $3.3 \pm 0.6$ & $3.3 \pm 0.3$ & $3.1 \pm 0.2$ & & $3.2 \pm 0.1^{\mathrm{A}, \mathrm{B}}$ & $3.4 \pm 0.4^{\mathrm{B}}$ & $3.0 \pm 0.3^{\mathrm{A}}$ & * \\
\hline$\Sigma$ SFA & $22.9 \pm 4.0$ & $21.0 \pm 0.6$ & $21.9 \pm 0.7$ & & $21.5 \pm 0.8$ & $21.6 \pm 1.0$ & $21.1 \pm 0.8$ & \\
\hline $16: 1 n 7$ & $3.6 \pm 0.8$ & $3.5 \pm 0.2$ & $3.3 \pm 0.3$ & & $3.5 \pm 0.3^{\mathrm{A}, \mathrm{B}}$ & $3.6 \pm 0.4^{\mathrm{B}}$ & $3.3 \pm 0.3^{\mathrm{A}}$ & * \\
\hline $18: \ln 9$ & $24.9 \pm 11.6$ & $24.6 \pm 0.9$ & $29.4 \pm 1.4$ & & $28.4 \pm 2.5^{C}$ & $25.4 \pm 1.1^{\text {В }}$ & $30.6 \pm 1.3^{\mathrm{A}}$ & ** \\
\hline $18: 1 n 7$ & $2.3 \pm 1.2$ & $2.3 \pm 1.3$ & $3.0 \pm 0.2$ & & $3.0 \pm 0.2^{\mathrm{B}}$ & $3.0 \pm 0.1^{\mathrm{B}}$ & $3.2 \pm 0.2^{\mathrm{A}}$ & ** \\
\hline 20:1n9 & $1.5 \pm 0.4^{\mathrm{A}}$ & $0.8 \pm 0.1^{\mathrm{B}}$ & $1.3 \pm 0.1^{\mathrm{A}}$ & $* *$ & $1.3 \pm 0.2^{\mathrm{A}}$ & $1.0 \pm 0.2^{\mathrm{B}}$ & $1.4 \pm 0.2^{\mathrm{A}}$ & ** \\
\hline ¿MUFA & $32.3 \pm 11.7$ & $31.3 \pm 1.6$ & $36.9 \pm 1.1$ & & $36.4 \pm 2.4^{C}$ & $33.2 \pm 1.4^{\mathrm{B}}$ & $38.7 \pm 1.3^{\mathrm{A}}$ & ** \\
\hline $18: 2 \mathrm{n} 6$ & $13.4 \pm 2.3^{\mathrm{A}}$ & $20.6 \pm 0.6^{\mathrm{B}}$ & $14.2 \pm 0.8^{\mathrm{A}}$ & ** & $12.8 \pm 1.0^{\mathrm{A}}$ & $16.8 \pm 3.9^{\text {В }}$ & $13.1 \pm 1.4^{\mathrm{A}}$ & ** \\
\hline $18: 3 n 6$ & $1.5 \pm 0.1^{\mathrm{B}}$ & $0.9 \pm 0.2^{\mathrm{A}}$ & $0.8 \pm 0.1^{\mathrm{A}}$ & $* *$ & $1.2 \pm 0.2^{\mathrm{B}}$ & $0.6 \pm 0.5^{\mathrm{A}}$ & $0.7 \pm 0.6^{\mathrm{A}, \mathrm{B}}$ & * \\
\hline $18: 3 n 3$ & $2.0 \pm 0.3$ & $2.1 \pm 0.1$ & $1.8 \pm 0.1$ & & $1.8 \pm 0.2$ & $1.8 \pm 0.3$ & $1.8 \pm 0.2$ & \\
\hline $20: 2 n 6$ & $0.7 \pm 0.1$ & $0.7 \pm 0.0$ & $0.8 \pm 0.1$ & & $0.7 \pm 0.1$ & $0.6 \pm 0.1$ & $0.7 \pm 0.1$ & \\
\hline $20: 3 n 6$ & $0.5 \pm 0.1$ & $0.4 \pm 0.1$ & $0.5 \pm 0.1$ & & $0.4 \pm 0.1$ & $0.2 \pm 0.2$ & $0.3 \pm 0.2$ & \\
\hline $20: 4 n 6$ & $2.3 \pm 0.3^{\mathrm{A}}$ & $1.7 \pm 0.2^{B}$ & $2.3 \pm 0.2^{\mathrm{A}}$ & ** & $2.1 \pm 0.2^{C}$ & $1.8 \pm 0.2^{\mathrm{B}}$ & $2.4 \pm 0.2^{\mathrm{A}}$ & ** \\
\hline $20: 3 n 3$ & $0.2 \pm 0.0$ & $0.2 \pm 0.0$ & $0.2 \pm 0.1$ & & $0.2 \pm 0.0$ & $0.1 \pm 0.0$ & $0.2 \pm 0.0$ & \\
\hline $20: 5 n 3$ & $5.6 \pm 1.3$ А В & $6.5 \pm 0.6^{\mathrm{B}}$ & $4.7 \pm 0.7^{\mathrm{A}}$ & * & $5.4 \pm 1.2^{\mathrm{A}}$ & $6.5 \pm 0.6^{B}$ & $5.0 \pm 0.6^{\mathrm{A}}$ & ** \\
\hline $22: 5 \mathrm{n} 6$ & $0.2 \pm 0.0^{\mathrm{B}}$ & $0.2 \pm 0.0^{\mathrm{B}}$ & $0.3 \pm 0.0^{\mathrm{A}}$ & * & $0.2 \pm 0.0^{\mathrm{B}}$ & $0.1 \pm 0.1^{\mathrm{A}}$ & $0.1 \pm 0.1^{\mathrm{A}, \mathrm{B}}$ & * \\
\hline $22: 5 n 3$ & $1.4 \pm 0.4^{\mathrm{B}}$ & $1.9 \pm 0.1^{\mathrm{A}}$ & $1.6 \pm 0.3$ А В & * & $1.5 \pm 0.4^{\mathrm{A}}$ & $1.9 \pm 0.2^{B}$ & $1.6 \pm 0.2^{\mathrm{A}}$ & ** \\
\hline $22: 6 n 3$ & $15.7 \pm 3.2^{\text {B }}$ & $11.2 \pm 0.3^{\mathrm{A}}$ & $12.9 \pm 1.0$ А В & * & $14.0 \pm 0.7$ & $13.0 \pm 1.6$ & $12.6 \pm 1.0$ & \\
\hline ¿PUFA & $44.8 \pm 7.8$ & $47.7 \pm 1.2$ & $41.2 \pm 1.6$ & & $41.6 \pm 2.0^{\mathrm{A}}$ & $44.9 \pm 2.4^{B}$ & $39.9 \pm 1.2^{\mathrm{A}}$ & ** \\
\hline$\Sigma \mathrm{n} 3$ & $26.1 \pm 5.2$ & $23.0 \pm 0.9$ & $22.1 \pm 1.4$ & & $23.9 \pm 1.9^{\text {B }}$ & $24.4 \pm 1.4^{\text {B }}$ & $22.2 \pm 1.0 \mathrm{~A}$ & $* *$ \\
\hline$\Sigma \mathrm{n} 6$ & $18.5 \pm 2.8^{\mathrm{A}}$ & $24.4 \pm 0.7^{\text {B }}$ & $18.8 \pm 0.4^{\mathrm{A}}$ & & $17.4 \pm 0.8^{\mathrm{A}}$ & $20.1 \pm 3.2^{\text {В }}$ & $17.2 \pm 0.7 \mathrm{~A}$ & ** \\
\hline $\mathrm{n} 3 / \mathrm{n} 6$ & $1.4 \pm 0.1^{\mathrm{A}}$ & $0.9 \pm 0.0^{\mathrm{B}}$ & $1.2 \pm 0.1^{\mathrm{C}}$ & & $1.4 \pm 0.1$ & $1.3 \pm 0.3$ & $1.3 \pm 0.1$ & \\
\hline
\end{tabular}

$\mathrm{A}, \mathrm{B}, \mathrm{C}=$ values in the same row for each product (eggs and caviar) with a different letter are significantly different, ${ }^{*}=p<0.05{ }^{* *}=p<0.01$. SFA $=$ Saturated Fatty Acids; MUFA $=$ MonoUnsaturated Fatty Acids; PUFA = PolyUnsaturated Fatty Acids. 


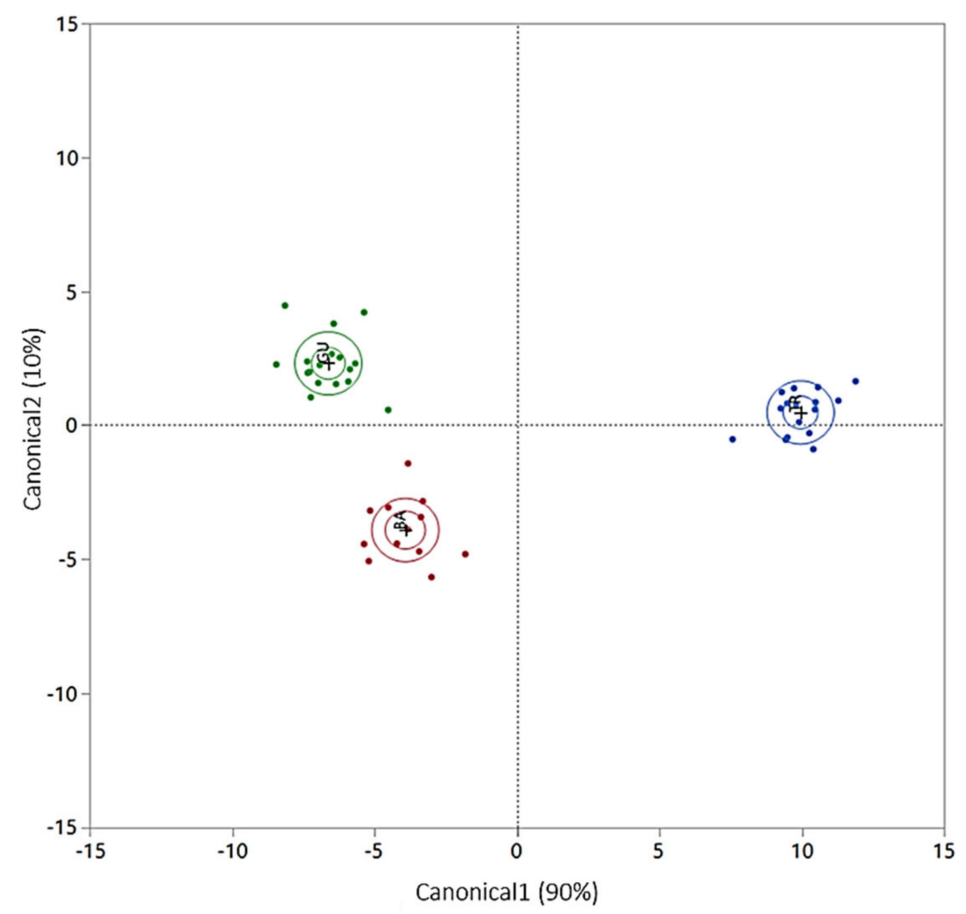

Figure 1. Canonical Plot of the Linear Discriminant Analysis (LDA) performed on eggs and caviar samples, using the sturgeon species as a discriminant factor. In the plot, each group is associated with a $95 \%$ confidence ellipse for the mean and a $50 \%$ prediction ellipsoid. Legend: green $\bullet=A$. gueldenstaedtii eggs and caviar, blue $\bullet=A$. transmontanus eggs and caviar, red $\bullet=A$. baerii eggs and caviar.

Table 3. Analysis of variance (ANOVA) by groups on first (C1) and second (C2) canonical functions obtained by LDA analysis performed on fatty acids data.

\begin{tabular}{|c|c|c|c|c|}
\hline \multicolumn{5}{|c|}{ Eggs and Caviar } \\
\hline Species & Siberian A. baerii & Russian A. gueldenstaedtii & White A.transmontanus & Sion \\
\hline $\mathbf{n}$ & 13 & 16 & 17 & \\
\hline $\mathrm{C} 1$ & $-3.9 \pm 1.0^{\mathrm{A}}$ & $-6.6 \pm 0.1^{B}$ & $10.0 \pm 1.0^{\mathrm{C}}$ & $* *$ \\
\hline $\mathrm{C} 2$ & $-3.9 \pm 1.2^{\mathrm{A}}$ & $2.3 \pm 1.0^{\mathrm{B}}$ & $0.48 \pm 0.8^{C}$ & $* *$ \\
\hline
\end{tabular}

The factors included in the LDA model were selected by a stepwise backward approach. Thus, we employed in the model such variables associated with a $p<0.05$ by means of analysis of covariance among all the variables. Sixteen fatty acids were selected and included in the arrangement of the discriminant model, allowing $100 \%$ of cases in the training set to be correctly grouped. The variables that highly correlated with Canonical1 (correlation loading $|>0.5|$ ) were represented by EPA, PUFA, OA, MUFA, 14:0 and ARA, whereas the highest correlation loadings ( $|>0.5|)$ between the variables and Canonical2 were associated with 20:1 n9, DHA, LA, DPA and 14:0. As shown in Figure 1 and Table 3, a suitable group separation was obtained in the bi-plot determined by the two canonicals, $\mathrm{C} 1$ and C2 $(p<0.01)$. Particularly, Siberian sturgeon eggs and caviar samples (red dots) were characterized by negative values for both $\mathrm{C} 1$ and $\mathrm{C} 2$, Russian sturgeon eggs and caviar samples (green dots) were characterized by positive values for $\mathrm{C} 1$ and negative values for $\mathrm{C} 2$, and White sturgeon eggs and caviar samples (blue dots) were characterized by positive values for both $\mathrm{C} 1$ and $\mathrm{C} 2$.

\subsection{Fatty acid Composition of Lipid Fractions}

It is well known that fatty acid composition of sturgeon eggs reflects the fatty acids composition of feed supplied to fish. In previous publications, Wirth et al. $[18,19]$ suggested that different factors, 
including the environment, can influence the lipid deposition in fish tissues. Particularly, the authors proposed that during the gonadogenesis, SFA and MUFA from female fish lipid reserves are mainly catabolized to provide the necessary energy for the pathways involved in eggs synthesis, whereas PUFA, especially long chain $\mathrm{n} 3$ fatty acids, are accumulated in eggs' lipids. Thus, they demonstrated that the fatty acid pattern in the different lipid fractions of eggs differed considerably, gathering that they should be estimated separately, even because of their different biological function $[18,19]$. For this reason, we analyzed the fatty acids pattern in the individual lipid fractions, phospholipids (PL) and neutral lipids (NL), of egg samples collected in our study. Results are shown in Table 4.

In Table 4, it is shown that the different lipid fractions (PL and NL) noticeably differed from each other if considering their fatty acids composition. In accordance with Gessner et al. [11], we did not observe considerable interspecific variations in the FA profile of PL but greater variations of the NL fraction. The most interesting results are related to the differences in OA, LA, ALA, ARA, EPA and DHA content between the two fractions within the same species. In all three groups, we found OA, LA and ALA in higher amounts in NL (ranging from $25.7 \%$ to $32.4 \%$ for OA, from $13.9 \%$ to $22.0 \%$ for LA and from 2.1 to $2.2 \%$ for ALA, ) in all cases reaching an amount two times, or more, higher than in the PL fraction. Conversely, we found ARA, EPA and DHA in higher amounts in the PL fraction (ranging from $3.0 \%$ to $3.9 \%$ for ARA, from $6.8 \%$ to $10.8 \%$ for EPA and from $16.6 \%$ to $19.7 \%$ for DHA). The only divergence in testing significance emerged in the A. baerii eggs group, in which no significant differences were detected in EPA and DHA content. This phenomenon could be mainly due to the great variability registered in data distribution for EPA and DHA in the A. baerii group (higher standard deviations). However, the n3:n6 ratio resulted in all cases as significantly higher in the PL fractions, where it reached values between 1.8, in White sturgeon eggs, and 2.5, in Siberian sturgeon eggs. Our results matched with literature data $[18,30]$ and they may be explained by the known existing relationship between the sturgeon lipid consumption through the diet and the specific biological function of different fatty acids. It can be suggested that OA, LA and ALA, highly representative in sturgeon feed formulations, are mainly stocked in the triacylglycerol fraction of oil droplets in yolk, as energy sources for the hatchlings. On the contrary, ARA, EPA and DHA may be particularly representative in the PL fraction because they are implicated in prostaglandine and eicosanoids formation in fish cell membranes, as previously suggested by other authors [18,30-32]. Particularly, it is known that PUFA of n3 series are incorporated into the phospholipid fraction of vitellogenin and transferred via the serum to the eggs during the gonadogenesis [33]. EPA and DHA are known to play a primary role in the embryonic development of fish, being fundamental for the development of nervous tissue and for maintaining the structural and functional integrity of cell membranes [27-29]. EPA, in particular, would be involved in the modulation of steroidogenesis in the male fish gonad and, therefore, in the regulation of spermatogenesis, influencing the rate of egg fertilization [9]. Moreover, it is known that the ARA is involved in the embryonic development of fish immune system, thus affecting the survival, development and growth of the fry [26,34]. In the last decade, the role of the ARA in the diet has received more and more attention, since it has been recognized to lead to potential benefits on the reproductive performances. Bruce et al. [35] and Mazorra et al. [36] reported an improvement in the percentage of hatching and larval survival following ARA supplementation in the diet of sea bass (Dicentrarchus labrax) and halibut (Hipoglossus hipoglossus) breeders. Consequently, in order to optimize the aquaculture production, it would be desirable to decrease the level of linoleic acid and increase the level of arachidonic acid in sturgeon diets, getting as close as possible to the situation of wild fish, improving the growth and the reproduction performances of sturgeons. The FA profiles of eggs detected in this study, represented by a similar phospholipid content among different species, suggested a more conservative composition of PL in all the involved species. This phenomenon indicated a selective FA inclusion in oocytes during the gonadogenesis and the formation of eggs' membranes. 
Table 4. Fatty acid (FA) composition (g/100 g of FA) of individual lipid fractions (phospholipids, NL and neutral lipids, NL) of egg samples from different sturgeon species. Data are expressed as mean \pm standard deviation.

\begin{tabular}{|c|c|c|c|c|c|c|c|c|c|}
\hline \multicolumn{10}{|c|}{ Eggs } \\
\hline Sturgeon Species & \multicolumn{3}{|c|}{ Siberian A. baerii } & \multicolumn{3}{|c|}{ Russian A. gueldenstaedtii } & \multicolumn{3}{|c|}{ White A. transmontanus } \\
\hline $\mathbf{n}$ & \multicolumn{3}{|c|}{5} & \multicolumn{3}{|c|}{5} & \multicolumn{3}{|c|}{5} \\
\hline Fraction & PL & NL & & PL & NL & & PL & NL & \\
\hline Fatty acids (g/100 g) & & & Sign. & & & Sign. & & & Sign. \\
\hline $14: 0$ & $2.1 \pm 0.5$ & $1.3 \pm 0.1$ & & $2.3 \pm 0.5$ & $1.7 \pm 0.2$ & & $2.1 \pm 0.2$ & $1.9 \pm 0.3$ & \\
\hline $16: 0$ & $22.2 \pm 10.3$ & $17.5 \pm 1.5$ & & $21.4 \pm 2.3$ & $16.4 \pm 3.0$ & & $22.3 \pm 1.4$ & $17.5 \pm 1.5$ & $*$ \\
\hline 18:0 & $8.6 \pm 3.2$ & $2.2 \pm 0.3$ & * & $9.3 \pm 0.7$ & $2.6 \pm 0.7$ & $* *$ & $7.5 \pm 0.4$ & $2.5 \pm 0.3$ & $* *$ \\
\hline$\Sigma$ SFA & $32.9 \pm 15.1$ & $21.1 \pm 2.0$ & & $33.0 \pm 5.3$ & $20.7 \pm 3.9$ & $*$ & $31.9 \pm 3.1$ & $21.8 \pm 2.0$ & $* *$ \\
\hline $16: 1 \mathrm{n} 7$ & $1.8 \pm 0.8$ & $4.1 \pm 0.3$ & $* *$ & $1.9 \pm 0.3$ & $4.1 \pm 0.8$ & ** & $2.0 \pm 0.2$ & $3.8 \pm 0.4$ & $* *$ \\
\hline $18: 1 \mathrm{n} 9$ & $15.8 \pm 8.9$ & $32.4 \pm 3.5$ & $*$ & $14.8 \pm 1.7$ & $25.7 \pm 4.8$ & $*$ & $18.4 \pm 1.6$ & $31.8 \pm 2.6$ & $* *$ \\
\hline $18: 1 \mathrm{n} 7$ & $2.2 \pm 1.1$ & $2.9 \pm 0.3$ & & $2.4 \pm 0.2$ & $2.9 \pm 0.6$ & & $2.2 \pm 0.3$ & $2.9 \pm 0.4$ & \\
\hline $20: 1 n 9$ & $2.7 \pm 1.4$ & $1.2 \pm 0.2$ & & $2.0 \pm 0.5$ & $0.8 \pm 0.1$ & * & $2.8 \pm 0.6$ & $1.2 \pm 0.1$ & $* *$ \\
\hline$\Sigma$ MUFA & $22.6 \pm 12.7$ & $40.5 \pm 4.2$ & & $21.1 \pm 3.0$ & $33.4 \pm 6.4$ & $*$ & $25.4 \pm 2.8$ & $39.7 \pm 3.3$ & $* *$ \\
\hline $18: 2 \mathrm{n} 6$ & $4.0 \pm 1.1$ & $13.9 \pm 0.9$ & $* *$ & $5.8 \pm 0.5$ & $22.0 \pm 4.1$ & $* *$ & $4.6 \pm 0.6$ & $15.4 \pm 2.1$ & $* *$ \\
\hline $18: 3 n 6$ & $1.2 \pm 0.2$ & $1.7 \pm 0.2$ & $*$ & $1.2 \pm 0.1$ & $1.1 \pm 0.3$ & & $1.1 \pm 0.2$ & $1.0 \pm 0.1$ & \\
\hline $18: 3 n 3$ & $1.3 \pm 0.2$ & $2.2 \pm 0.2$ & $* *$ & $1.3 \pm 0.1$ & $2.4 \pm 0.5$ & $*$ & $1.2 \pm 0.2$ & $2.1 \pm 0.3$ & $*$ \\
\hline $20: 2 \mathrm{n} 6$ & $1.7 \pm 0.4$ & $0.6 \pm 0.1$ & $* *$ & $1.9 \pm 0.1$ & $0.7 \pm 0.1$ & $* *$ & $1.7 \pm 0.2$ & $0.7 \pm 0.1$ & $* *$ \\
\hline $20: 3 n 6$ & $1.6 \pm 0.4$ & $0.6 \pm 0.1$ & $*$ & $1.5 \pm 0.1$ & $0.5 \pm 0.1$ & $* *$ & $1.6 \pm 0.4$ & $0.6 \pm 0.1$ & $* *$ \\
\hline $20: 4 n 6$ & $3.5 \pm 1.2$ & $1.6 \pm 0.3$ & & $3.0 \pm 0.5$ & $1.4 \pm 0.5$ & $*$ & $3.9 \pm 0.5$ & $1.8 \pm 0.2$ & $* *$ \\
\hline $20: 3 n 3$ & $1.0 \pm 0.1$ & $0.3 \pm 0.0$ & $* *$ & $1.1 \pm 0.1$ & $0.3 \pm 0.0$ & $* *$ & $1.0 \pm 0.2$ & $0.3 \pm 0.0$ & $* *$ \\
\hline $20: 5 n 3$ & $8.4 \pm 3.0$ & $4.4 \pm 0.8$ & & $10.8 \pm 1.0$ & $5.9 \pm 1.8$ & $*$ & $6.8 \pm 0.8$ & $4.0 \pm 0.8$ & $*$ \\
\hline $22: 5 \mathrm{n} 6$ & $0.7 \pm 0.4$ & $0.2 \pm 0.0$ & & $0.8 \pm 0.4$ & $0.2 \pm 0.1$ & & $0.8 \pm 0.1$ & $0.2 \pm 0.1$ & $* *$ \\
\hline $22: 5 n 3$ & $1.4 \pm 0.8$ & $1.4 \pm 0.2$ & & $2.0 \pm 0.4$ & $2.2 \pm 0.4$ & & $1.2 \pm 0.3$ & $1.7 \pm 0.4$ & \\
\hline $22: 6 n 3$ & $19.7 \pm 7.3$ & $11.5 \pm 1.4$ & & $16.6 \pm 0.9$ & $9.3 \pm 2.0$ & $* *$ & $18.7 \pm 1.1$ & $10.7 \pm 1.9$ & $* *$ \\
\hline$\Sigma$ PUFA & $44.6 \pm 14.8$ & $38.5 \pm 3.5$ & & $45.8 \pm 2.2$ & $45.9 \pm 10.1$ & & $42.6 \pm 3.3$ & $38.5 \pm 5.9$ & \\
\hline$\Sigma \mathrm{n} 3$ & $32.4 \pm 11.3$ & $20.6 \pm 2.6$ & & $32.3 \pm 1.2$ & $21.0 \pm 4.8$ & * & $29.5 \pm 2.3$ & $19.7 \pm 3.4$ & * \\
\hline$\Sigma \mathrm{n} 6$ & $12.7 \pm 3.5$ & $18.9 \pm 1.4$ & $*$ & $14.6 \pm 1.1$ & $26.1 \pm 5.1$ & $*$ & $13.7 \pm 1.5$ & $19.9 \pm 2.4$ & $*$ \\
\hline n3/n6 & $2.5 \pm 0.2$ & $1.1 \pm 0.1$ & $* *$ & $2.2 \pm 0.1$ & $0.8 \pm 0.0$ & $* *$ & $1.8 \pm 0.7$ & $1.0 \pm 0.1$ & $* *$ \\
\hline
\end{tabular}

${ }^{*}=p<0.05,{ }^{* *}=p<0.01$. SFA = Saturated Fatty Acids; MUFA = MonoUnsaturated Fatty Acids; PUFA = PolyUnsaturated Fatty Acids. 


\subsection{Proximate Composition and Fatty acid Composition of Sturgeon Fillets}

Results obtained by proximate composition analysis on sturgeon meat fillets from different breeding species and size are presented in Table 5 .

Table 5. Proximate composition (g/100 g) of fillet meat samples from different sturgeon species and size. Data are expressed as mean \pm standard deviation.

\begin{tabular}{|c|c|c|c|c|}
\hline & & Flesh & & \\
\hline Sturgeon Species & Siberian (A. baerii) & White (A. transmontanus) & White (A. transmontanus) & \\
\hline Farmed for & Caviar production & Caviar production & Meat production & \\
\hline Gender & Female & Female & Male & \\
\hline Average fish weight & $5-8 \mathrm{~kg}$ & $30-50 \mathrm{~kg}$ & $6-10 \mathrm{~kg}$ & \\
\hline n & 5 & 5 & 5 & \\
\hline \multicolumn{4}{|c|}{ Proximate composition } & Sign. \\
\hline Moisture & $75.5 \pm 1.6$ & $75.2 \pm 3.3$ & $77.7 \pm 1.1$ & \\
\hline Ash & $1.3 \pm 0.2$ & $1.2 \pm 0.3$ & $1.1 \pm 0.0$ & \\
\hline Lipid & $5.6 \pm 1.7$ & $3.9 \pm 2.5$ & $2.6 \pm 0.8$ & \\
\hline Protein & $17.6 \pm 0.5^{\mathrm{A}}$ & $19.6 \pm 0.8^{\mathrm{B}}$ & $18.6 \pm 0.5^{\mathrm{A}, \mathrm{B}}$ & $* *$ \\
\hline
\end{tabular}

Results obtained by proximate composition analysis on sturgeon meat matched with those of previous studies conducted on A. baerii and A. transmontanus muscle by other authors [15,37]. No great differences were detectable among the groups, with the exception of protein content, observing higher values in female White sturgeon meat $(19.6 \%)$, followed by the male White sturgeon meat $(18.6 \%)$ and then by the female Siberian sturgeon meat (17.6\%). It is reasonable to suppose that genetic factors are at the basis of the differences observed in protein content, as suggested by Badiani et al. [15]. Lipid values ranged from $2.6 \%$ in white sturgeon and $5.6 \%$ in Siberian sturgeon. These outcomes confirmed the fact that sturgeon meat can be classified as a medium-fat high-protein product in the scale proposed by Stansby [38], making it an appealing food for market, containing a restrained fat content with a high nutritional value (essential fatty acids). Moreover, it can be suggested that the medium-fat meat of Siberian sturgeon could be considered suitable for possible processing techniques, such as smoking and canning [17], that usually lead to a greater appreciation of the product by consumers.

Results obtained by fatty acid composition on sturgeon meat fillets are presented in Table 6. 
Table 6. Fatty acid composition ( $\mathrm{g} / 100 \mathrm{~g}$ of FA) of fillets from different sturgeon species. Data are expressed as mean \pm standard deviation.

\begin{tabular}{|c|c|c|c|c|}
\hline \multicolumn{5}{|c|}{ Flesh } \\
\hline Sturgeon Species & Siberian (A. baerii) & White (A.transmontanus) & White (A. transmontanus) & \\
\hline Farmed for & Caviar production & Caviar production & Meat production & \\
\hline Gender & Female & Female & Male & \\
\hline Average fish weight & $5-8 \mathrm{~kg}$ & $30-50 \mathrm{~kg}$ & $6-10 \mathrm{~kg}$ & \\
\hline $\mathbf{n}$ & 5 & 5 & 5 & \\
\hline \multicolumn{4}{|c|}{ Fatty acid (g/100 g) } & Sign \\
\hline $14: 0$ & $1.3 \pm 0.1$ & $1.9 \pm 0.6$ & $1.7 \pm 1.3$ & \\
\hline $16: 0$ & $15.5 \pm 0.7$ & $17.6 \pm 0.8$ & $16.9 \pm 1.9$ & \\
\hline $18: 0$ & $2.4 \pm 0.5^{\mathrm{A}}$ & $3.9 \pm 1.4^{\mathrm{A}}$ & $5.9 \pm 1.2^{\mathrm{B}}$ & $* *$ \\
\hline$\Sigma S F A$ & $19.2 \pm 0.6^{\mathrm{A}}$ & $23.4 \pm 1.6^{\mathrm{B}}$ & $24.5 \pm 3.3^{\text {В }}$ & $* *$ \\
\hline $16: 1 \mathrm{n} 7$ & $3.3 \pm 0.6$ & $3.4 \pm 1.1$ & $2.9 \pm 2.0$ & \\
\hline $18: 1 \mathrm{n} 9$ & $37.5 \pm 2.6^{\mathrm{A}}$ & $34.0 \pm 2.3^{\mathrm{A}}$ & $25.0 \pm 6.3^{\text {В }}$ & $* *$ \\
\hline $18: 1 \mathrm{n} 7$ & $2.8 \pm 0.1$ & $3.1 \pm 0.1$ & $2.9 \pm 0.3$ & \\
\hline $20: 1 n 9$ & $1.8 \pm 0.1^{\mathrm{A}}$ & $2.2 \pm 0.5^{\mathrm{A}}$ & $0.5 \pm 1.1^{\mathrm{B}}$ & $* *$ \\
\hline$\Sigma$ MUFA & $45.5 \pm 2.8^{\mathrm{A}}$ & $42.7 \pm 3.5^{\mathrm{A}}$ & $31.3 \pm 5.5^{\text {В }}$ & $* *$ \\
\hline $18: 2 \mathrm{n} 6$ & $16.1 \pm 0.3$ & $11.9 \pm 0.7$ & $14.1 \pm 5.1$ & \\
\hline $18: 3 n 6$ & $1.3 \pm 0.4^{\mathrm{A}}$ & $0.4 \pm 0.1^{\mathrm{B}}$ & $0.4 \pm 0.2^{\mathrm{B}}$ & $* *$ \\
\hline $18: 3 n 3$ & $2.7 \pm 0.4^{\mathrm{A}}$ & $1.6 \pm 0.4^{\mathrm{B}}$ & $1.9 \pm 0.8^{\mathrm{A} \mathrm{B}}$ & * \\
\hline $20: 2 n 6$ & $0.9 \pm 0.2$ & $0.7 \pm 0.2$ & $0.8 \pm 0.3$ & \\
\hline $20: 3 n 6$ & $0.5 \pm 0.2 \mathrm{~A} \mathrm{~B}$ & $0.3 \pm 0.0^{\mathrm{A}}$ & $0.6 \pm 0.2^{\mathrm{B}}$ & $*$ \\
\hline $20: 4 n 6$ & $1.6 \pm 0.4 \mathrm{~A}^{\prime}$ & $2.0 \pm 0.8^{\mathrm{A}}$ & $3.6 \pm 0.9^{B}$ & $* *$ \\
\hline $20: 3 n 3$ & $0.2 \pm 0.1$ & $0.2 \pm 0.0$ & $0.2 \pm 0.2$ & \\
\hline $20: 5 \mathrm{n} 3$ & $3.9 \pm 0.8^{\mathrm{A}}$ & $5.7 \pm 0.8^{\mathrm{A}, \mathrm{B}}$ & $8.6 \pm 4.5^{\mathrm{B}}$ & * \\
\hline $22: 5 \mathrm{n} 3$ & $0.9 \pm 0.6$ & $1.4 \pm 0.3$ & $1.8 \pm 0.7$ & \\
\hline $22: 6 n 3$ & $7.3 \pm 1.5^{\mathrm{A}}$ & $9.7 \pm 1.9 \mathrm{~A}, \mathrm{~B}$ & $12.3 \pm 3.2^{\mathrm{B}}$ & * \\
\hline$\Sigma$ PUFA & $35.3 \pm 2.7^{\mathrm{A}}$ & $33.9 \pm 2.1 \mathrm{~A}$ & $44.2 \pm 2.9^{\text {B }}$ & $* *$ \\
\hline$\sum \mathrm{n} 3$ & $15.0 \pm 2.2 \mathrm{~A}$ & $18.5 \pm 1.5^{\mathrm{A}, \mathrm{B}}$ & $24.7 \pm 7.4^{\text {В }}$ & * \\
\hline$\Sigma \mathrm{n} 6$ & $20.4 \pm 1.0$ & $15.4 \pm 1.2$ & $19.5 \pm 5.0$ & \\
\hline $\mathrm{n} 3 / \mathrm{n} 6$ & $0.7 \pm 0.1$ & $1.2 \pm 0.1$ & $1.4 \pm 0.9$ & \\
\hline
\end{tabular}

Fatty acids composition of sturgeon meat showed a prevalence of unsaturated fatty acids on saturated fatty acids in all samples. Interesting differences were found among different groups. Particularly, meat obtained by the males of White sturgeon seemed to be enriched in PUFA (44.2\%) in comparison to meat obtained by female sturgeons of the same species, designated to the production of caviar (33.9\%), and the one obtained by the lightweight caviar-designated females of Siberian sturgeon (35.2\%). This outcome allowed us to confirm, as previously mentioned above (Sections 2.1 and 2.2), that the metabolism of female sturgeons operates a selective deposition of fatty acids fundamental for reproduction (ARA, EPA, DHA) in eggs, leading to the stocking of the other FA (mainly represented by OA, LA and ALA) in fish fat deposits. Related to this, we found the highest level of EPA and DHA in male White sturgeon meat $(8.6 \%$ and $12.3 \%$, respectively), followed by female White sturgeon meat (5.7\% and 9.7\%) and female Siberian sturgeon meat (3.9\% and 7.3\%). The high levels of EPA and DHA in analyzed samples should be kept in great consideration, since these fatty acids are strictly related to the nutritional quality of the product, which appears to be characterized by a reduced lipid content of a high nutritional value. Moreover, this could be useful in order to promote sturgeon meat on the market, dismantling its actual consideration as a by-product of caviar and enforcing the activity of sturgeon aquaculture even for meat production. The n3:n6 ratio ranged from 0.7 to 1.4 with no significant differences, resulting lower than values (around 4) previously reported in literature for $A$. transmontanus and A. baerii fillets $[15,17,37]$. It is worth to mention that this difference is highly influenced by the content of LA that, in our study, is four times higher than reported by the above-mentioned authors (11.9\%-16.1\%). This difference could be easily explained by the modifications which occurred in aquafeed formulations during the last years, in order to contain producers' costs 
and to increase aquaculture sustainability, substituting fish meals and oils with vegetable ones [39], enriched in LA. In Badiani et al. [15,37], sturgeon diets, in fact, were only represented by fish meals and oils. Comparing our data with those of Palmegiano et al. [40] on Siberian sturgeon meat, it is possible to observe that LA and n3/n6 values obtained in our research perfectly agree with those referred to fish fed with recent commercial diets (control group). MUFA were detected in higher values in meat of Siberian sturgeons (45.5\%) and female White sturgeons (42.7\%) than in the males of white Sturgeon $(31.5 \%)$. The most representative FA among MUFA was oleic acid in all samples, ranging from 25\% and $37.5 \%$, in accordance with results obtained by previous studies on fatty acids analysis in A. baerii and $A$. transmontanus meat $[15,17,37,40]$.

\subsection{Color Parameters of Sturgeon Fillets}

We evaluated the colorimetric features of collected sturgeon fillets. Results of colorimetric analysis (redness, $\mathrm{a}^{*}$, yellowness, $\mathrm{b}^{*}$, lightness, $\mathrm{L}^{*}$ and Chroma, $\mathrm{C}^{*}$ ) are shown in Table 7 and Figure 2.

Table 7. Color parameters ( $a^{*}$, redness, $b^{*}$, yellowness, $L^{*}$, brightness, $C^{*}$, Chroma) of sturgeon fillets collected in our study. Average values were calculated as mean \pm standard deviation of each group. $\mathrm{a}^{*}$, $b^{*}, L^{*}$ values were obtained by two replicates in three different sites of each fillet.

\begin{tabular}{|c|c|c|c|c|}
\hline & & Flesh & & \\
\hline Sturgeon Species & Siberian (A. baerii) & White (A. transmontanus) & White (A. transmontanus) & \\
\hline Farmed for & Caviar production & Caviar production & Meat production & \\
\hline Gender & Female & Female & Male & \\
\hline Average fish weight & $5-8 \mathrm{~kg}$ & $30-50 \mathrm{~kg}$ & $6-10 \mathrm{~kg}$ & \\
\hline \multicolumn{4}{|c|}{ Color parameters } & Sign. \\
\hline$a^{*}$ & $-0.86 \pm 3.29$ & $-1.98 \pm 1.87$ & $-3.27 \pm 1.04$ & \\
\hline$b^{*}$ & $6.41 \pm 1.91^{\mathrm{B}}$ & $2.99 \pm 0.88^{\mathrm{A}}$ & $2.56 \pm 1.59^{\mathrm{A}}$ & * \\
\hline $\mathrm{L}^{*}$ & $57.78 \pm 7.85$ & $53.76 \pm 2.46$ & $54.56 \pm 2.70$ & \\
\hline$C^{*}$ & $7.15 \pm 1.67^{\text {B }}$ & $3.97 \pm 0.79 \mathrm{~A}$ & $4.36 \pm 1.19^{\mathrm{A}}$ & * \\
\hline
\end{tabular}

Color parameters obtained in this study were different from those previously detected in literature in sturgeon meat from other species and hybrids [41,42]. Our data showed a negative value for the redness parameter, indicating a tendency to green in all samples analyzed, different to other authors' findings. This phenomenon could be obviously due to the species-specific characteristics of sturgeon meat. $b^{*}$ values were always positive, ranging between 2.56 in White sturgeon to 6.41 in Siberian sturgeon, showing a significantly different tendency to yellow in meat of the two species. $L^{*}$ value refers to the lightness of the meat surface. The detected values covered a range between 50 and 60, comparable to values previously found by Ünal Şengör et al. [41] and Wedekind [42], indicating an intermediate position between the dark and the bright appearance in all samples. In the end, we calculated $\mathrm{C}^{*}$ value, referring to the Chroma, finding values in a range from 3.97 in White sturgeon, and 7.15 in Siberian sturgeon, with a significant difference between the two species. The bigger the $C^{*}$ parameter is, the more "definite/saturated" the color is perceived. Our values indicated that all analyzed sturgeon species meat samples were characterized by almost achromatic hues, commonly recognized as different shades of grey. 


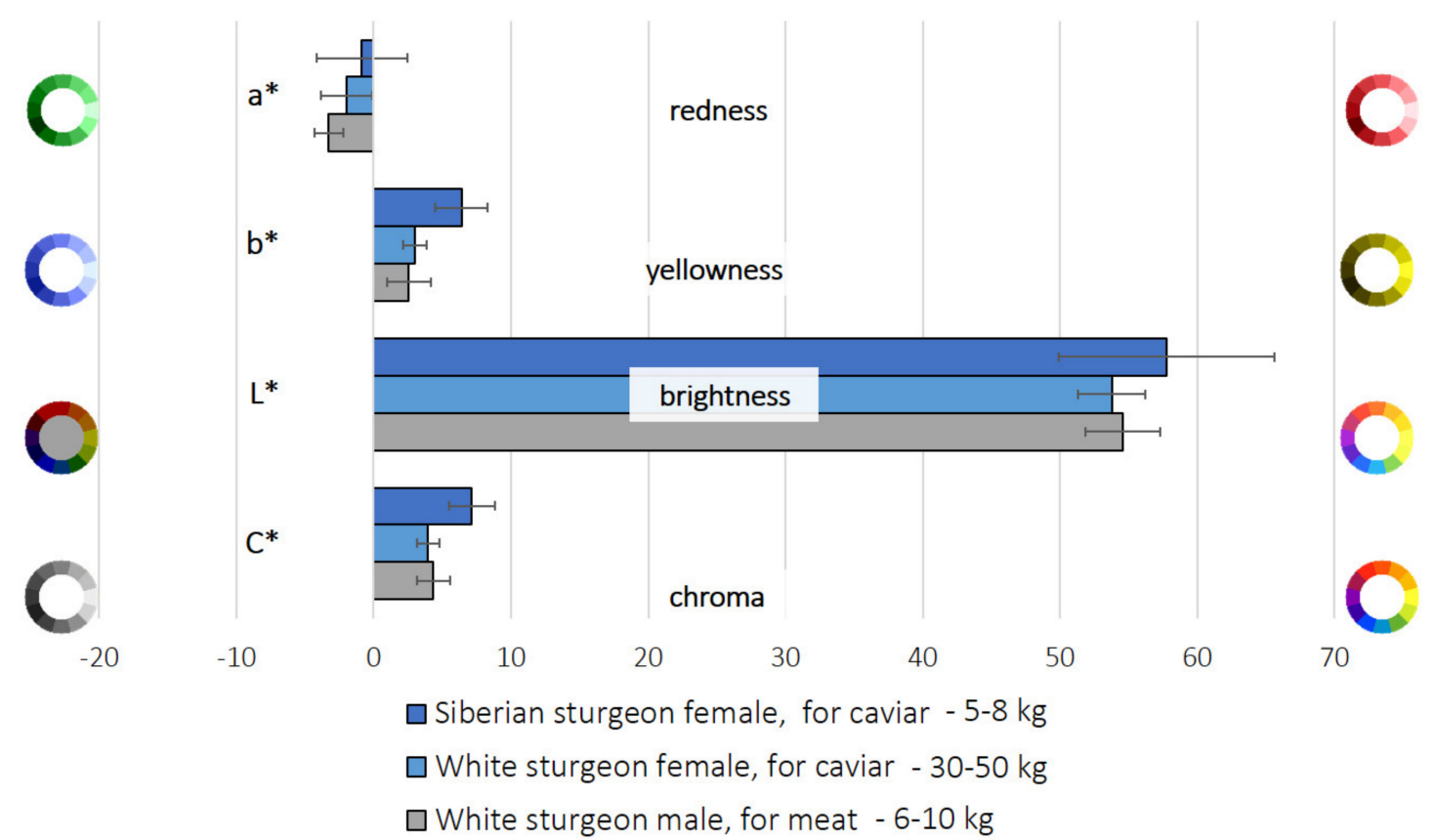

Figure 2. Color parameters (redness, $a^{*}$, yellowness, $b^{*}$, lightness, $L^{*}$ and Chroma, $C^{*}$ ) values (Minolta Chroma Meter II) in different sturgeon species fillets. Average values were calculated as mean \pm standard deviation of each group. $a^{*}, b^{*}, L^{*}$ values were obtained by two replicates in three different sites of each fillet.

Results obtained by colorimetric analysis mainly showed a difference in meat from the two species (A. baerii and A. transmontanus), suggesting that the color is a species-specific characteristic. No differences were found between male and female samples of $A$. transmontanus, suggesting that body composition and flesh appearance were not affected by a sex-effect. The characterization of sturgeon meat's typical features may be of primary importance in order to increase its importance in marketing of aquaculture products, being related to consumers' acceptance. As mentioned before, Italian consumers seem not to appreciate sturgeon meat, being not accustomed with it. The visual appearance of the product may be a crucial aspect to consider and to characterize in order to promote its acceptance by consumers, demonstrating and spreading the knowledge that the grey flesh feature is not related to a low quality of meat, but a specific characteristic of sturgeon meat.

\section{Materials and Methods}

\subsection{Samples Collection}

This study was carried out in cooperation with Agroittica Lombarda S.p.A. (BS), the most important Italian Company in sturgeon farming and caviar production. Fifteen sturgeon egg samples were collected during caviar preparation in the lab facilities of the production plant, belonging to the following species: Acipenser baerii $(n=5)$, Acipenser gueldenstaedtii $(n=5)$ and Acipenser transmontanus $(n=5)$. Roes were simply extracted from sturgeons after the separation from their connective tissue. After about six months of maturation in the storage room, 33 canned caviar samples were collected from the same species as above: Acipenser baerii $(n=8)$, Acipenser gueldenstaedtii $(n=12)$ and Acipenser transmontanus $(n=11)$. Caviar was obtained through a simple and consolidated procedure, by light salting $(3.6 \%-3.8 \%)$ of roes and freeze storage $\left(-2{ }^{\circ} \mathrm{C}\right)$ in $500 \mathrm{~g}$ tin cans. Both the eggs and the caviar samples were transported to the laboratory and stored at $-20{ }^{\circ} \mathrm{C}$ until the analyses were performed.

At the same time, 15 specimens of sturgeon meat from three different species were sampled: 5 samples from $A$. baerii females (fish weight $5-8 \mathrm{~kg}$ ), 5 samples from $A$. transmontanus females (fish weight $30-50 \mathrm{Kg}$ ) and 5 samples from $A$. transmontanus males (fish weight $6-10 \mathrm{Kg}$ ). The meat slices, 
about $5 \mathrm{~cm}$ thick, were obtained by cross-cutting in a retro-cranial position of a freshly gutted fresh fish. They were then vacuum-packed and frozen at $-20{ }^{\circ} \mathrm{C}$ until analysis. After adequate thawing they were portioned, to create the most representative samples possible of the whole slice. A portion equal to about $10 \mathrm{~g}$ of apical meat, a central one and a basal one was then taken. Subsequently, they were finely chopped with a knife and prepared for the chemical analysis.

\subsection{Proximate Composition and Fatty Acid Analysis}

Proximate composition was determined on eggs, caviar and sturgeon meat using standard methods [43]. Moisture content was determined by drying samples in an oven at $105^{\circ} \mathrm{C}$ for $16-18 \mathrm{~h}$ (Association of Official Analytical Chemists (AOAC) Method 950.46). Total protein was determined by the Kjeldahl method (AOAC Method 940.25). For the analysis, an automated distillation unit (BÜCHI Labortechnik AG, Flawil, Switzerland) was used. Ash was determined by incineration of the sample in a muffle furnace at $550{ }^{\circ} \mathrm{C}$ for $18 \mathrm{~h}$ (AOAC Method 938.08).

The extraction and determination of total lipids was performed according to the Folch and Lees method [44] with a chloroform:methanol mixture $(2: 1, v / v)$, using $0.7-1.0 \mathrm{~g}$ of sample, according to its lipid content. The preparation of fatty acid methyl esters was performed according to Christie [45]. Briefly, the lipid sample $(20 \mathrm{mg})$ was dissolved in $10 \%$ methanolic hydrogen chloride $(2 \mathrm{~mL})$. A $1 \mathrm{~mL}$ solution of tricosanoic acid $\left(1 \mathrm{mg} \mathrm{mL}^{-1}\right)$ in toluene was added as an internal standard. The sample was sealed and heated at $50^{\circ} \mathrm{C}$ overnight. Then, $2 \mathrm{~mL}$ of a $1 \mathrm{M}$ potassium carbonate solution and $5 \mathrm{~mL}$ of $5 \% \mathrm{NaCl}$ were added to each sample. The fatty acids methyl esters (FAME) were extracted with $2 \times 2 \mathrm{~mL}$ of hexane and the mixture was evaporated under nitrogen. The sample was dissolved in $1 \mathrm{~mL}$ hexane. Fatty acid analysis was carried out by capillary chromatography on an 6890 series gas-chromatograph (Agilent Technologies, Santa Clara, CA, USA) fitted with an automatic sampler model 7683 and Flame Ionization Detector (FID) by the same provider. $1 \mu \mathrm{L}$ of sample was injected into the gas-chromatograph, in split mode (split ratio 1:100), with helium as a carrier gas, with a flow rate of $1.0 \mathrm{~mL} \mathrm{~min}{ }^{-1}$ and an inlet pressure of 16.9. A HP-Innowax fused silica capillary column (30 m $\times 0.25 \mathrm{~mm}$ internal diameter, $0.25 \mu \mathrm{m}$ film thickness, Agilent Technologies) was used to separate fatty acid methyl esters. The oven temperature program for separation was from 100 to $180^{\circ} \mathrm{C}$ at $3^{\circ} \mathrm{C} \mathrm{min}^{-1}$, then from 180 to $250{ }^{\circ} \mathrm{C}$ at $2.5^{\circ} \mathrm{C} \mathrm{min}-1$ and held for $10 \mathrm{~min}$. Fatty acids were identified relative to known external standards and were expressed as percentage of total fatty acids.

\subsection{Lipid Fractions Separation}

Lipids extracted from egg samples were separated into fractions by a Solid Phase Extraction (SPE) method. Extraction of neutral lipids was performed using a DSC-NH $\mathrm{N}_{2}$ disposable cartridge column (6 mL) (Supelco Inc., Bellefonte, PA, USA), according to the procedure of Kaluzny et al. [46]. The cartridge column was equilibrated by rinsing twice with $3 \mathrm{~mL}$ of hexane using a Visiprep ${ }^{\mathrm{TM}} \mathrm{SPE}$ Vacuum Manifold (Supelco Inc., Bellefonte, PA, USA). $10 \mathrm{mg}$ of lipids dissolved in $100 \mu \mathrm{l}$ of chloroform were loaded onto the column and the chloroform was pulled through. Thereafter, the column was eluted with $4 \mathrm{~mL}$ of a chloroform-2-propanol 2:1 mixture, to obtain the neutral lipid fraction (NL). Then, $4 \mathrm{~mL}$ of methanol was used to elute phospholipids (PL). The flow rate was adjusted to approximately 3-5 $\mathrm{mL} / \mathrm{min}$. Each fraction collected was dried under a stream of nitrogen, dissolved in $2 \mathrm{~mL}$ of $10 \%$ methanolic hydrogen chloride, trans-esterified and analyzed as described in paragraph 4.2.

\subsection{Color Measurements in Fillets}

Color measurements of the flesh samples were performed in three different sites. Color was measured using a Minolta Chroma Meter II Reflectance instrument (Minolta Camera Co. Ltd., Osaka, Japan). Results were recorded as $\mathrm{a}^{*}, \mathrm{~b}^{*}, \mathrm{~L}^{*}$ values, where $\mathrm{a}^{*}$ describes redness, $\mathrm{b}^{*}$ yellowness and $\mathrm{L}^{*}$ lightness. Chroma values (brightness, $\mathrm{C}^{*}$ ) were calculated according to the following equation: $\mathrm{C}^{*}$ $=\sqrt{a * 2+b * 2}$. Two measurements were taken on each site and the measuring head was rotated $90^{\circ}$ between each measurement. 


\subsection{Statistical Analysis}

The statistical analysis was performed using JMP Pro 14 (SAS Institute Inc., Cary, NC, USA). Normality and homoscedasticity of data distribution for eggs, caviar and sturgeon meat were tested by the Shapiro-Wilk test and Levene test, respectively. When both the conditions were confirmed, the comparisons between means was performed by analysis of variance (ANOVA), setting the different Acipenser species as the discriminating factor between groups. The Tukey's Honest Significant Difference test was used as a post-hoc test between each pair of groups. When normality and/or homoscedasticity were not confirmed, the comparison between means was performed by the Wilcoxon Ranks test. Significance was declared at $p<0.05\left(^{*}\right)$ and $p<0.01\left(^{* *}\right)$. Then, a multivariate statistical approach was employed on eggs and caviar fatty acids distribution. A Linear Discriminant Analysis (LDA) was performed involving fatty acids data in canonicals calculation, in order to generate a bi-plot where a clustering of different groups was perceptible. The LDA method was performed following a stepwise-backward approach, including variables in the model if $p$ values that achieved testing for the group variable by analysis of covariance were $<0.05$.

\section{Conclusions}

Results obtained in this work provided the characterization of food products obtained by sturgeons bred in Italy. Especially, caviar was characterized as a product with high nutritional value, even if its composition showed some variations from species to species. In comparison with the same products obtained by wild sturgeon stocks, some relevant differences were detected, particularly in the content of fatty acids that derive from aquafeed (above all, linoleic acid from vegetable oils). In our opinion, it would be desirable to find a way to decrease the level of linoleic acid and increase that of arachidonic acid in the diet of sturgeons, getting as close as possible to the situation of wild caviar, in order to optimize production in aquaculture and to deliver products with a more favorable lipid composition. On the other hand, all the matrices analyzed showed remarkable values of essential fatty acids that cover a fundamental role in human nutrition. Particularly, data strengthened the hypothesis that the selective deposition of EPA and DHA in eggs during the gonadogenesis occurs regardless of the type of diet supplied to fish. The outcomes of our research might be fundamental to enhance the knowledge about this product, in order to promote its acceptance by Italian consumers, spreading fair information about its nutritional quality and helping to dismantle its actual evaluation as a caviar by-product. Results of this investigation, in fact, showed that sturgeon meat from aquaculture is a product of undeniable commercial interest, represented by a reduced lipid content of notable nutritional value.

Author Contributions: Conceptualization, M.V. and V.M.M.; Formal analysis, A.L. and M.V.; Investigation, A.L., M.V. and T.M.; Methodology, M.V.; Project administration, V.M.M.; Supervision, F.B.; Validation, M.V., F.B. and V.M.M.; Visualization, A.L. and V.M.M.; Writing—original draft, A.L., F.B. and V.M.M.; Writing—review and editing, M.V., F.B., T.M. and V.M.M. All authors have read and agreed to the published version of the manuscript.

Funding: This research received no external funding.

Acknowledgments: The authors would like to thank Dr. Mario Pazzaglia, Head of Special Projects and Scientific External Relations in Agroittica Lombarda SpA, for his assistance with the collection and purchasing of sturgeon eggs, caviar and meat samples.

Conflicts of Interest: The authors declare no conflict of interest.

Ethical Approval: This article does not contain any experimental practice performed on animals by the authors. Only caviar and fillets' sampling was performed in order to develop the present research. No biological material was collected on alive animals. Authors guarantee that the farm involved in the study followed all the applicable guidelines for animal welfare established by harmonized EU rules. No approval by the institutional ethics committee was requested by University of Milan for this kind of research.

\section{References}

1. Bronzi, P.; Chebanov, M.; Michaels, J.T.; Wei, Q.; Rosenthal, H.; Gessner, J. Sturgeon meat and caviar production: Global update 2017. J. Appl. Ichthyol. 2019, 35, 257-266. [CrossRef] 
2. Chebanov, M.; Billard, R. The culture of sturgeons in Russia: Production of juveniles for stocking and meat for human consumption. Aquat. Living Resour. 2001, 14, 375-381. [CrossRef]

3. Bronzi, P.; Rosenthal, H.; Gessner, J. Global sturgeon aquaculture production: An overview. J. Appl. Ichthyol. 2011, 27, 169-175. [CrossRef]

4. Bronzi, P.; Rosenthal, H. Present and future sturgeon and caviar production and marketing: A global market overview. J. Appl. Ichthyol. 2014, 30, 1536-1546. [CrossRef]

5. CITES. CITES Trades Database for the Year 2018. Available online: https://trade.cites.org/ (accessed on 27 September 2019).

6. Parisi, G.; Terova, G.; Gasco, L.; Piccolo, G.; Roncarati, A.; Moretti, V.M.; Centoducati, G.; Gatta, P.P.; Pais, A. Current status and future perspectives of Italian finfish aquaculture. Rev. Fish Biol. Fish. 2014, 24, 15-73. [CrossRef]

7. Caprino, F.; Moretti, V.M.; Bellagamba, F.; Turchini, G.M.; Busetto, M.L.; Giani, I.; Paleari, M.A.; Pazzaglia, M. Fatty acid composition and volatile compounds of caviar from farmed white sturgeon (Acipenser transmontanus). Anal. Chim. Acta 2008, 617, 139-147. [CrossRef] [PubMed]

8. Bledsoe, G.E.; Bledsoe, C.D.; Rasco, B. Caviars and Fish Roe Products. Crit. Rev. Food Sci. Nutr. 2003, 43, 317-356. [CrossRef]

9. Ovissipour, M.; Rasco, B. Fatty acid and amino acid profiles of domestic and wild beluga (Huso huso) roe and impact on fertilization ratio. J. Aquac. Res. Dev. 2011, 2. [CrossRef]

10. DePeters, E.J.; Puschner, B.; Taylor, S.J.; Rodzen, J.A. Can fatty acid and mineral compositions of sturgeon eggs distinguish between farm-raised versus wild white (Acipenser transmontanus) sturgeon origins in California? Preliminary report. Forensic Sci. Int. 2013, 229, 128-132. [CrossRef]

11. Gessner, J.; Würtz, S.; Kirschbaum, F.; Wirth, M. Biochemical composition of caviar as a tool to discriminate between aquaculture and wild origin. J. Appl. Ichthyol. 2008, 24, 52-56. [CrossRef]

12. Czesny, S.; Dabrowski, K.; Christensen, J.E.; Van Eenennaam, J.; Doroshov, S. Discrimination of wild and domestic origin of sturgeon ova based on lipids and fatty acid analysis. Aquaculture 2000, 189, 145-153. [CrossRef]

13. Mol, S.; Turan, S. Comparison of proximate, fatty acid and amino acid compositions of various types of fish roes. Int. J. Food Prop. 2008, 11, 669-677. [CrossRef]

14. Hamzeh, A.; Moslemi, M.; Karaminasab, M.; Khanlar, M.A.; Faizbakhsh, R.; Batebi Navai, M.; Tahergorabi, R. Amino acid composition of roe from wild and farmed beluga sturgeon (Huso huso). J. Agric. Sci. Technol. 2015, 17, 357-364.

15. Badiani, A.; Stipa, S.; Nanni, N.; Gatta, P.P.; Manfredini, M. Physical indices, processing yields, compositional parameters and fatty acid profile of three species of cultured sturgeon (genus Acipenser). J. Sci. Food Agric. 1997, 74, 257-264. [CrossRef]

16. Vaccaro, A.M.; Buffa, G.; Messina, C.M.; Santulli, A.; Mazzola, A. Fatty acid composition of a cultured sturgeon hybrid (Acipenser naccarii x A. baerii). Food Chem. 2005, 93, 627-631. [CrossRef]

17. Paleari, M.A.; Beretta, G.; Grimaldi, P.; Vaini, F. Composition of muscle tissue of farmed white sturgeon (Acipenser transmontanus) with particular reference to lipidic content. J. Appl. Ichthyol. 1997, 13, 63-66. [CrossRef]

18. Wirth, M.; Kirschbaum, F.; Gessner, J.; Krüger, A.; Patriche, N.; Billard, R. Chemical and biochemical composition of caviar from different sturgeon species and origins. Nahr. Food 2000, 44, 233-237. [CrossRef]

19. Wirth, M.; Kirschbaum, F.; Gessner, J.; Williot, P.; Patriche, N.; Billard, R. Fatty acid composition in sturgeon caviar from different species: Comparing wild and farmed origins. Int. Rev. Hydrobiol. 2002, 87, 629-636. [CrossRef]

20. Ovissipour, M.; Al-Qadiri, H.M.; Lu, X.; Hu, Y.; Ross, C.F.; Van Eenennaam, J.P.; Doroshov, S.I.; Rasco, B. The effect of white sturgeon (Acipenser transmontanus) ovarian fat deposition on caviar yield and nutritional quality: Introducing image processing method for sturgeon ovary fat determination. Int. Aquat. Res. 2015, 7, 263-272. [CrossRef]

21. Gussoni, M.; Greco, F.; Vezzoli, A.; Paleari, M.A.; Moretti, V.M.; Beretta, G.; Caprino, F.; Lanza, B.; Zetta, L. Monitoring the effects of storage in caviar from farmed Acipenser transmontanus using chemical, SEM, and NMR methods. J. Agric. Food Chem. 2006, 54, 6725-6732. [CrossRef]

22. Shin, J.H.; Oliveira, A.C.M.; Rasco, B.A. Quality attributes and microbial storage stability of caviar from cultivated white sturgeon (Acipenser transmontanus). J. Food Sci. 2010, 75, 3-8. [CrossRef] [PubMed] 
23. Henderson, R.J. Fatty acid metabolism in freshwater fish with particular reference to polyunsaturated fatty acids. Arch. Für Tierernaehr. 1996, 49, 5-22. [CrossRef] [PubMed]

24. Chen, I.-C.; Chapman, F.A.; Wei, C.-I.; Portier, K.M.; O'Keefe, S. Differentiation of Cultured and Wild Sturgeon (Acipenser oxyrinchus desotoi) Based on Fatty Acid Composition. J. Food Sci. 1995, 60, 631-635. [CrossRef]

25. Das, U.N. Essential Fatty acids-A Review. Curr. Pharm. Biotechnol. 2006, 7, 467-482. [CrossRef] [PubMed]

26. Yanes-Roca, C.; Rhody, N.; Nystrom, M.; Main, K.L. Effects of fatty acid composition and spawning season patterns on egg quality and larval survival in common snook (Centropomus undecimalis). Aquaculture 2009, 287, 335-340. [CrossRef]

27. Bell, J.G.; Castell, J.D.; Tocher, D.R.; MacDonald, F.M.; Sargent, J.R. Effects of different dietary arachidonic acid : Docosahexaenoic acid ratios on phospholipid fatty acid compositions and prostaglandin production in juvenile turbot (Scophthalmus maximus). Fish Physiol. Biochem. 1995, 14, 139-151. [CrossRef]

28. Bell, J.G.; Ashton, I.; Secombes, C.J.; Weitzel, B.R.; Dick, J.R.; Sargent, J.R. Dietary lipid affects phospholipid fatty acid compositions, eicosanoid production and immune function in Atlantic salmon (Salmo salar). Prostaglandins Leukot. Essent. Fat. Acids 1996, 54, 173-182. [CrossRef]

29. Lee, S.M. Review of the lipid and essential fatty acid requirements of rockfish (Sebastes schlegeli). Aquac. Res. 2001, 32, 8-17. [CrossRef]

30. Mukhopadhyay, T.; Ghosh, S. Lipid profile and fatty acid composition of two silurid fish eggs. J. Oleo Sci. 2007, 56, 399-403. [CrossRef]

31. Prabhakara Rao, P.G.; Balaswamy, K.; Narsing Rao, G.; Jyothirmayi, T.; Karuna, M.S.L.; Prasad, R.B.N. Lipid classes, fatty acid and phospholipid composition of roe lipids from Catla catla and Cirrhinus mrigala. Int. Food Res. J. 2013, 20, 275-279.

32. Tocher, D.R.; Sargent, J.R. Analyses of lipids and fatty acids in ripe roes of some Northwest European marine fish. Lipids 1984, 19, 492-499. [CrossRef] [PubMed]

33. Bransden, M.P.; Battaglene, S.C.; Goldsmid, R.M.; Dunstan, G.A.; Nichols, P.D. Broodstock condition, egg morphology and lipid content and composition during the spawning season of captive striped trumpeter, Latris lineata. Aquaculture 2007, 268, 2-12. [CrossRef]

34. Tocher, D.R. Fatty acid requirements in ontogeny of marine and freshwater fish. Aquac. Res. 2010, 41, 717-732. [CrossRef]

35. Bruce, M.; Oyen, F.; Bell, G.; Asturiano, J.F.; Farndale, B.; Carrillo, M.; Zanuy, S.; Ramos, J.; Bromage, N. Development of broodstock diets for the European Sea Bass (Dicentrarchus labrax) with special emphasis on the importance of $\mathrm{n}-3$ and $\mathrm{n}-6$ highly unsaturated fatty acid to reproductive performance. Aquaculture 1999, 177, 85-97. [CrossRef]

36. Mazorra, C.; Bruce, M.; Bell, J.G.; Davie, A.; Alorend, E.; Jordan, N.; Rees, J.; Papanikos, N.; Porter, M.; Bromage, N. Dietary lipid enhancement of broodstock reproductive performance and egg and larval quality in Atlantic halibut (Hippoglossus hippoglossus). Aquaculture 2003, 227, 21-33. [CrossRef]

37. Badiani, A.; Anfossi, P.; Fiorentini, L.; Gatta, P.P.; Manfredini, M.; Nanni, N.; Stipa, S.; Tolomelli, B. Nutritional composition of cultured sturgeon (Acipenser spp.). J. Food Compos. Anal. 1996, 9, 171-190. [CrossRef]

38. Stansby, M.E. Chemical Characteristics of Fish Caught in the Northeast Pacific Ocean. Mar. Fish. Rev. 1976, 38, 1-11.

39. Gatlin, D.M.; Barrows, F.T.; Brown, P.; Dabrowski, K.; Gaylord, T.G.; Hardy, R.W.; Herman, E.; Hu, G.; Krogdahl, Å.; Nelson, R.; et al. Expanding the utilization of sustainable plant products in aquafeeds: A review. Aquac. Res. 2007, 38, 551-579. [CrossRef]

40. Palmegiano, G.B.; Agradi, E.; Forneris, G.; Gai, F.; Gasco, L.; Rigamonti, E.; Sicuro, B.; Zoccarato, I. Spirulina as a nutrient source in diets for growing sturgeon (Acipenser baeri). Aquac. Res. 2005, 36, 188-195. [CrossRef]

41. Ünal Şengör, G.F.; Alakavuk, D.Ü.; Tosun, Ş.Y.; Ulusoy, Ş. The chemical and sensory quality of smoked sturgeon (Huso huso): A case study. J. Aquat. Food Prod. Technol. 2010, 19, 310-317. [CrossRef]

42. Wedekind, H. Chemical composition and processability of farmed sturgeon hybrids with special emphasis on Bester. Int. Rev. Hydrobiol. 2002, 87, 621-627. [CrossRef]

43. AOAC. Official Methods of Analysis of the Association of Official Analytical Chemists; Association of Official Analytica Chemists: Arlington, VA, USA, 1996.

44. Folch, J.; Lees, M.; Sloane Stanley, G.H. A simple method for the isolation and purification of total lipids from animal tissues. J. Biol. Chem. 1957, 226, 497-509. [PubMed] 
45. Christie, W.W. Preparation of derivatives of fatty acids. In Lipid Analysis: Isolation, Separation and Structural Analysis of Lipids; The Oily Press: Bridgwater, UK, 2003; pp. 205-225.

46. Kaluzny, M.A.; Duncan, L.A.; Merrit, M.V.; Epps, D.E. Rapid separation of lipid classes in high yield and purity using bonded phase columns. J. Lipid Res. 1985, 26, 135-140. [PubMed]

(C) 2020 by the authors. Licensee MDPI, Basel, Switzerland. This article is an open access article distributed under the terms and conditions of the Creative Commons Attribution (CC BY) license (http://creativecommons.org/licenses/by/4.0/). 